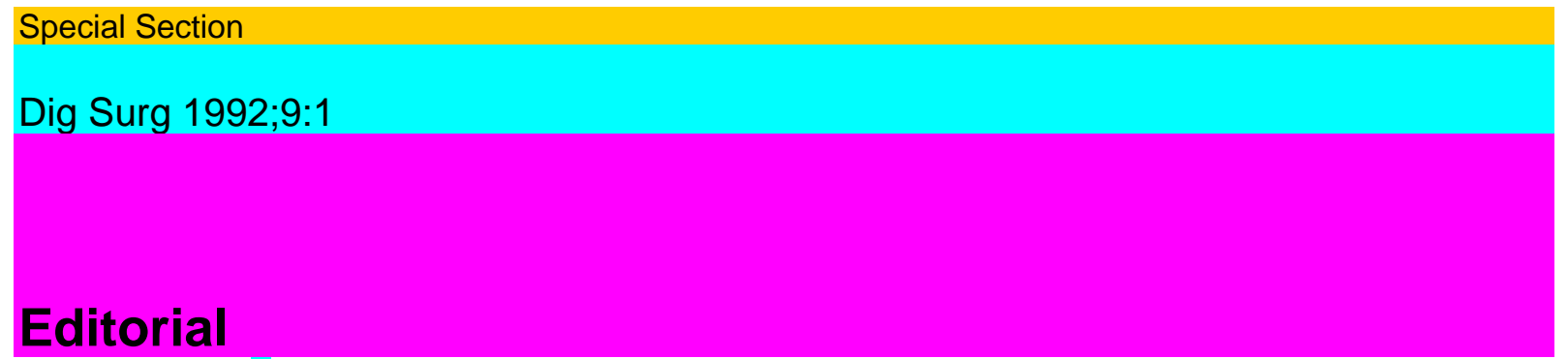

\title{
E.H. Farthmann
}

Editor in Chief, Freiburg

Digestive Surgery is now in its 9th year of publication. Since the beginning it has been steadily improving in the overall quality of the published work. This has been attained by a rigid peerreview process and was testified by the fact that Digestive Surgery in the meanwhile is listed in Current Contents.

Starting now, the volumes of Digestive Surgery will be increased from four to six issues per year. It is planned to publish 'Special Issues' dealing with recent developments in one of the most intriguing fields of digestive surgery. The last year issue on laparoscopic surgery (8-2) was published as a sort of a pilot project, and, in the light of the positive reactions of our readers, we believe that this way should be continued in the future.

Our editorial aim is to bring different perspective to bear on research and clinical practice - the perspectives of experts in research and surgical techniques from all over the world. Our aim, too, is to look at the interaction of theoretical aspects and clinical routine, at the influence of basic research on modern surgical practice, and at the close relationship between all fields of hepatogastroen-terology and digestive surgery: at the options that are open, the dilemmas that we face, the choices we must take. In particular, we hope that Digestive Surgery helps you to come to terms with ever increasing complex issues and, at the same time, stimulates and informs you by interesting studies, profound reviews and sometimes conflicting opinions.

As other journals, Digestive Surgery often had to deal with the problems of redundant publication and conflicts of interests, issues which engage the attention of editors everywhere. We hope that we were able to manage those problems in appropriate ways and we will try hard to do so in the future.

We would also like to take this opportunity of inviting you to write to us at any time with your comments, which may be published in a 'correspondence' section, and suggestions. It is always a great pleasure, as well as highly stimulating, to hear personally from you. 